\title{
Soil Properties and Soil Management Practices in Commercial Organic and Conventional Vegetable Farms in Kathmandu Valley
}

\author{
Gautam Shrestha \\ Himalayan College of Agricultural Sciences and Technology (HICAST), Kathmandu, Nepal \\ e-mail:shresthagautam@live.com
}

\begin{abstract}
Soil management practices determine the long term productivity of soil. A comparative study of commercial organic and conventional vegetable farming systems was carried out to find out impact of different farming systems on soil properties. This study was executed in Kathmandu valley (Kathmandu, Bhaktapur and Lalitpur districts) among 30 organic and 30 conventional commercial vegetable farmers. Semi-structured questionnaire survey and soil physical and chemical analysis were performed to gather the required information. Results showed that bulk soil $\mathrm{pH}$ was significantly higher in the organic field than in the conventional field. Soil organic matter and available soil potassium were significantly higher in amount in the organic farm than in the conventional farm. Total soil nitrogen content and available soil nitrogen content were significantly higher in amount in the conventional farm than in the organic farm. Conventional farmers were applied significantly higher amount of chicken manure and biozyme as compared to organic farmers. Organic farmers applied significantly higher amount of urban compost and bone meal as compared to conventional farmers. Farmers perceived productivity was increasing in trend in the organic farms whereas it was declining in the conventional farms.
\end{abstract}

Key words: soil fertility, organic agriculture, conventional agriculture

\section{Introduction}

Soil is the natural resource in the earth which is the source of food for living organisms. With the dawn of agricultural civilization, human learnt to use soil for food production. To increase the productivity, later human started to add organic manure in the soil. This type of agriculture is known as traditional agriculture. This type of farming is still in practice in the remote parts of Nepal (MoAC 2008). Invention of ammonia synthesis process in 1909 and consequent development of Haber Bosch process provided an option to add nitrogen nutrient in easily available form through chemical fertiliser. Later on, human discovered mineral deposits of other plant nutrients (e.g. phosphorus, potassium and sulphur) as well. Human started to append different chemical fertiliser to increase crop productivity. This type of farming is termed as conventional agriculture. In consequence of excessive use of chemical fertiliser and pesticide, we saw environmental pollution, biodiversity loss, human health problem (Eyhorn et al. 2002, Hall \&
Moffitt 2002). We learnt conventional agriculture is not a sustainable option for the healthy mother earth. Hence, going back to the origin, human has given a new name to an age old agriculture 'organic agriculture'. With more insight and sophistication, organic agriculture is expected to fulfil the food demand of human population in the future as well (Badgley $e t$ al. 2007).

Organic agriculture movement was initiated in industrialised countries - Britain, Germany, Japan and the US in 1930s and 40s (Lotter 2003). Within a century of initiation, organic agriculture had spread in many parts of the world. Many studies have been conducted comparing organic and conventional farming systems. Comparative studies began with yield comparison (Mader et al. 2002), economics (Offermann \& Nieberg 2000) and soil parameters (Lotter 2003).

Comparing soil properties, Birkhofer et al. (2008) established significantly higher soil acidity in the 
organic wheat farms in comparison to conventional ones in Switzerland. In contrast, Deria et al. (2003) found no significant difference in soil acidity between organic and conventional wheat farms in Australia. Clark et al. (1998) and Liebig \& Doran (1999) presented significantly higher total soil nitrogen in the organic farm than in the conventional farm. In contrast, Clark et al. (1999) showed nitrogen availability is limited in the organic farming system. Monokrousos et al. (2006) found significantly higher extractable soil phosphorus content in organic asparagus field in comparison to conventional field. In contrast, Romanyà \& Rovira (2009) indicated significantly higher soil phosphorus content in conventional farm in comparison to organic farm. Andrist-Rangel et al. (2007) compared soil potassium content between conventional farm and organic farm from 1987 to 2004 in Sweden and found non-significant difference. Lotter (2003) indicated that organic farm can either have significantly higher or no significant difference in soil potassium content than in conventional farm. Cardelli et al. (2004) revealed significantly higher soil organic carbon content in organic farm in comparison to conventional farm with vegetable crops. They published results after four years of research in which they were applying only chemical fertiliser in conventional farm. In contrast, Chirinda et al. (2010) established non- significant difference in soil organic carbon content after 11 years of experiment among different farming systems.

There are few studies on soil physical properties comparing conventional and organic farm. In the study conducted by Zeiger \& Fohrer (2009), soil moisture content in the organic farm was relatively higher in comparison to conventional farm. Liebig \& Doran (1999) revealed significantly lower soil bulk density in organic farm in comparison to conventional farm. In contrast, Schjønning et al. (2002) and Chirinda et al. (2010) showed non- significant effect of contrasting farming systems in the soil bulk density.

Concerning commercial agriculture, government of Nepal has started promoting commercial organic and conventional farming since $10^{\text {th }}$ five year national development plan $(2002-2007)$. The continued government support can be noticed in the Nepal Agricultural Policy, 2004 and Agricultural Development Strategy (ADS) (ADB 7762-NEP 2013) as well.

Many studies have been published comparing different cropping systems. However, studies on vegetable based systems comparing soil nutrient status in farmers' field are lacking. This study aims to give a small impetus on the real world scenario i.e. commercial vegetable fields of the suburbs in Kathmandu valley than experiment field situation.

\section{Methodology \\ Study area}

Kathmandu valley consists of three districts namely Kathmandu, Lalitpur and Bhaktapur. These districts are densely populated (Zurick \& Rose 2009) areas in Nepal. Vegetable production is an age old traditional farming practice near the water resources in Kathmandu valley. Kathmandu valley is one of the areas with the highest vegetable productivity per unit area in Nepal (ABPSD 2012). Moreover, increasing population and demand for fresh vegetables have increased the area of commercial vegetable farming in the periurban areas in the valley. Furthermore, health conscious consumers dwelling in the city area are demanding for the organic vegetables; to supply the demand organic vegetable production area is also expanding (Bhandari 2006). The periurban commercial vegetable growing farmers in Kathmandu valley were selected for the study.

\section{Questionnaire survey}

Thirty farmers each growing vegetables following organic and conventional management methods were selected for the study. Questionnaire was prepared in Nepali language and pre-tested and amended before the survey. Farmers from Bhaktapur (15), Kathmandu (25) and Lalitpur (20) districts were interviewed using semi-structured questionnaire to gather information about soil management aspects of the farm. Questionnaire survey and soil samples collection were done from May 15 to June 15, 2013. Farmers applied fertiliser in the field recently in February, 2013.

\section{Soil sample collection and analysis}

Soil samples were taken from the soil depth of 0 to 20 $\mathrm{cm}$. Both bulk and rhizospheric soil samples were collected from each farmer's field. For rhizospheric soil sample, soil from plant rhizosphere region was considered. For bulk soil sample, soil which was further away from the plant stand was taken. Soil samples for soil $\mathrm{pH}$ and available soil nitrogen determination were stored in the refrigerator.

For the determination of physical and chemical properties of soil, about $500 \mathrm{~g}$ of soil was air dried and sieved with $2 \mathrm{~mm}$ sieve and stored in the air tight plastic 
Gautam Shrestha/Soil properties and soil management.......

bags. Particle size analysis was done by Bouyoucos method with hydrometer, bulk density using measuring cylinder and particle density using pycnometer. Soil $\mathrm{pH}$ was measured using $0.01 \mathrm{M} \mathrm{CaCl}_{2}$ (calcium chloride) solution with the glass electrode $\mathrm{pH}$ meter. Soil organic matter content was determined by Walkley Black method using $0.1667 \mathrm{M} \mathrm{K}_{2} \mathrm{Cr}_{2} \mathrm{O}_{7}$ (potassium dichromate) solution. Available soil potassium content was determined with flame photometer using $1.0 \mathrm{~N}$ $\mathrm{CH}_{3} \mathrm{CHOONH}_{4}$ (ammonium acetate) extractant. Available soil phosphorus content was determined by modified Olsen's method with spectrophotometer using $0.5 \mathrm{M} \mathrm{NaHCO}$ (sodium bicarbonate) extractant. Available soil nitrogen content was determined with steam distillation method using $1.0 \mathrm{~N}$
$\mathrm{KCl}$ (potassium chloride) extractant and $\mathrm{MgO}-$ Devarda's alloy. Total soil nitrogen content was determined by Kjeldahl digestion and distillation method using digestion mixture $\left(\mathrm{Na}_{2} \mathrm{SO}_{4}\right.$ and $\left.\mathrm{CuSO}_{4}\right)$. The details of the procedures followed are given in FRSRD (1980) and Shrestha (2012).

\section{Results and Discussion \\ General characteristics}

Duration of farming varied among farmers from just a year to 15 years of experience in commercial farming. One of the organic farmers was doing organic farming for 20 years. Organic farmers were involved in farming for more duration (five years) in comparison to conventional farmers (three years) (Table 1).

Table 1. General characteristics of commercial organic and conventional farms in Kathmandu valley

\begin{tabular}{l|l|l|l}
\hline Parameters & Organic farm & Conventional farm & Level of significance* \\
\hline Nurnber of crops in a ye ar & $5.91 \pm 0.56$ & $4.80 \pm 0.49$ & ns \\
Area of farm (Ropari) & $10.5 \pm 1.81$ & $1769 \pm 4.09$ & ns \\
Years of farming & $4.73 \pm 0.87$ & $2.9 \pm 0.51$ & 0.038
\end{tabular}

* Level of significance of difference between two farming systems tested with independent samples T test, ns $=$ non-significant difference; 1 Ropani $=500 \mathrm{~m}^{2}$

\section{Crops}

Data were taken on at the most ten crops from each respondent. Results showed that about $10 \%$ organic farmers grew ten crops in the field in a year whereas only $6 \%$ conventional farmers were growing ten crops with commercial purpose. Tomato was the main crop in both organic and conventional commercial vegetable farms in Kathmandu valley (Figure 1).

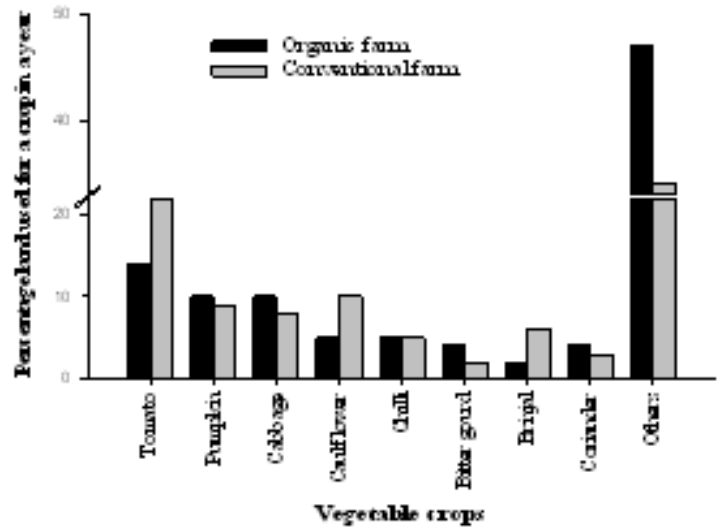

Fig. 1. Choice and diversity of vegetable crops in commercial organic and conventional farms (percentage coverage out of total area) in Kathmandu valley

\section{Soil properties}

Many organic farmers were growing vegetables in the coarse textured soil in comparison to conventional farmers (Table 2).

Table 2. Soil texture in commercial organic and conventional farms (percentage of soil samples out of 30 each) in Kathmandu valley

\begin{tabular}{l|l|l}
\hline Soil texture & $\begin{array}{l}\text { Organic farm } \\
\text { (percentage) }\end{array}$ & $\begin{array}{l}\text { Conventional farm } \\
\text { (percentage) }\end{array}$ \\
\hline Coarse & 33.3 & 100 \\
Medium & 50.0 & 633 \\
Fine & 16.7 & 26.7 \\
\hline
\end{tabular}

Organic vegetable farm had significantly higher bulk soil $\mathrm{pH}$ in comparison to conventional vegetable farm (Table 3). Available soil nitrogen content in the conventional vegetable farm was almost double in comparison to the organic farm. Total soil nitrogen content in the conventional vegetable farm was significantly higher in comparison to the organic farm. Available soil potassium content was significantly higher in the organically managed soil than in the conventionally managed soil (Table 3 ). 
Table 3. Soil physical and chemical properties in commercial organic and conventional farms (mean \pm standard error, out of 30 soil samples) in Kathmandu valley

\begin{tabular}{|c|c|c|c|}
\hline $\begin{array}{l}\text { Parameters } \\
\text { Soil physical properties }\end{array}$ & Organic farm & Conventional farm & Level of significance* \\
\hline Moisture content (percentage) & $29.70 \pm 1.44$ & $3052 \pm 1.28$ & ns \\
\hline Bulk density $\left(\mathrm{g} \mathrm{cm}^{-3}\right)$ & $1.09 \pm 0.02$ & $1.08 \pm 0.02$ & ns \\
\hline Particle density $\left(\mathrm{g} \mathrm{cm}^{-3}\right)$ & $2.09 \pm 0.04$ & $2.11 \pm 0.02$ & ns \\
\hline \multicolumn{4}{|l|}{ Soil chemic alp roperties } \\
\hline Rhizospheric soil $\mathrm{pH}$ & $5.66 \pm 0.11$ & $5.54 \pm 0.07$ & ns \\
\hline Bulk soil pH & $5.49 \pm 0.09$ & $5.29 \pm 0.06$ & 0.035 \\
\hline Organic matter (percentage) & $7.24 \pm 0.51$ & $6.08 \pm 0.28$ & 0.016 \\
\hline Available nitrogen (ppm) & $4492 \pm 18.21$ & $85.68 \pm 14.06$ & 0.045 \\
\hline Total nitrogen (percentage) & $0.22 \pm 0.01$ & $0.27 \pm 0.01$ & 0.006 \\
\hline Available phosphorus $\left(\mathrm{P}_{2} \mathrm{O}_{9} \mathrm{~kg} \mathrm{ha}^{-1}\right)$ & $1241.36 \pm 230.77$ & $874.91 \pm 96.31$ & ns \\
\hline Available potassium $\left(\mathrm{K}_{2} \mathrm{O} \mathrm{kg} \mathrm{ha} \mathrm{kg}^{-1}\right)$ & $705.89 \pm 111.17$ & $513.11 \pm 54.94$ & 0.041 \\
\hline
\end{tabular}

* Level of significance of difference between two farming systems tested with independent samples $\mathrm{T}$ test, ns $=$ non-significant difference.

\section{Fertiliser use}

Chemical fertiliser was applied only in the commercial conventional vegetable farms (Table 4). Conventional farmers were applying $8 \mathrm{~kg}$ nitrogen, $5.5 \mathrm{~kg}$ phosphorus and $5 \mathrm{~kg}$ potassium per ropani using chemical fertiliser in a year.

Chicken manure was applied significantly higher in amount by conventional vegetable grower than the organic farmer. In contrast, urban compost and bone meal application was significantly higher in amount by organic farmer in comparison to conventional farme (Table 4).

About $75 \%$ conventional vegetable farmer have applied lime in the field whereas only $35 \%$ of organic farmer have applied it once in the past (Table 4).

Table 4. Fertiliser use in commercial organic and conventional farms ((mean \pm standard error, out of 30 each) in Kathmandu valley

\begin{tabular}{|c|c|c|c|}
\hline Fertiliser (lg ropani ${ }^{-1}$ year $^{-1}$ ) & Organic farm & Conventional farm & $\begin{array}{l}\text { Level of } \\
\text { significance* }\end{array}$ \\
\hline \multicolumn{4}{|l|}{ Chemic al fer tiliser } \\
\hline Urea $(46 \% \mathrm{~N})$ & & $12.62 \pm 1.14$ & \\
\hline Diarumorium phosphate $(18 \% \mathrm{~N}, 46 \% \mathrm{P})$ & & $11.90 \pm 0.99$ & \\
\hline Muriate of potassium $(60 \% \mathrm{~K})$ & & $8.02 \pm 0.78$ & \\
\hline \multicolumn{4}{|l|}{ Organic manures } \\
\hline Chicken manure & $593.84 \pm 59.53$ & $999.36 \pm 152.12$ & 0.020 \\
\hline Famyard manure & $2228.54 \pm 195.40$ & $1964.62 \pm 241.62$ & ns \\
\hline Urban compost & $410.26 \pm 141.66$ & $74.00 \pm 8.45$ & 0.011 \\
\hline Mustard cake & $38.38 \pm 5.38$ & $32.79 \pm 3.13$ & ns \\
\hline Bone meal & $47.46 \pm 3.46$ & $17.09 \pm 3.48$ & 0.000 \\
\hline Compost mix & $1746.08 \pm 381.962$ & $2293.81 \pm 1040.42$ & ns \\
\hline Biozyme & $1.00 \pm 0.00$ & $2.27 \pm 0.38$ & 0.000 \\
\hline Application of lime ( $\%$ famers) & $75.50 \pm 24.78$ & $35.37 \pm 11.35$ & \\
\hline
\end{tabular}




\section{Irrigation}

Organic farmers were using mainly flood method of irrigation $(50.0 \%)$ whereas hose method was the main method $(50.0 \%)$ of irrigation among conventional farmers. Non-conventional irrigation methods such as drip irrigation and sprinkler irrigation were more common in the conventional farms in comparison to the organic farms (Table 5).

Table 5. Irrigation methods in commercial organic and conventional farms (percentage respondents out of 30 each, multiple response) in Kathmandu valley

\begin{tabular}{l|l|l}
\hline Irrigation method & $\begin{array}{l}\text { Organic farm } \\
\text { (percentage) }\end{array}$ & $\begin{array}{l}\text { Correntional } \\
\text { farm } \\
\text { (percentage) }\end{array}$ \\
\hline Flood inigation & 53.3 & 30.0 \\
Drip inigation & 13.3 & 13.3 \\
Sprinkler irrigation & 6.7 & 36.7 \\
Hose method & 26.7 & 50.0 \\
\hline
\end{tabular}

\section{Farmers' indigenous knowledge}

A chi-squared test for goodness of fit using farmers' perception of soil texture as expected value and results of soil textural analysis as observed value was performed. The observed chi-squared value for two degrees of freedom and p-value of 0.005 was 10.79 whereas tabulated value was only 10.60 . Hence, we can say that the farmers' perception about the soil texture was in agreement with the mechanical analysis (Figure 2).

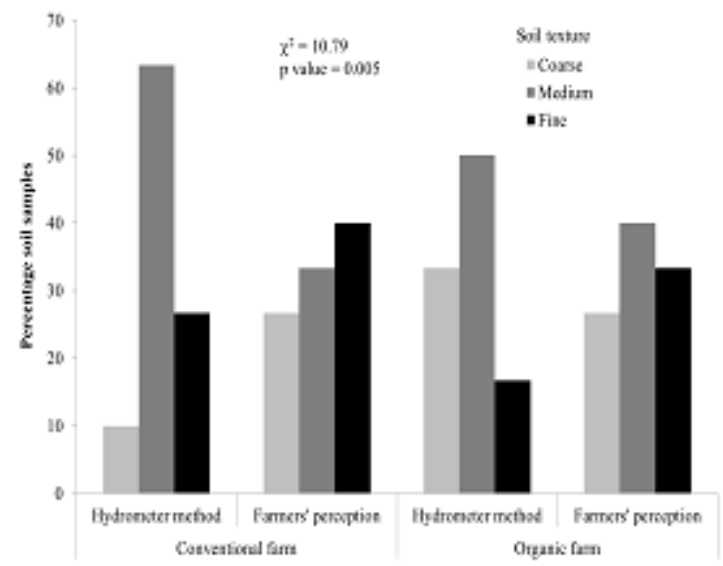

Fig. 2. Parity test on farmers' perception of soil texture and results of mechanical analysis (percentage of 30 soil samples each) in Kathmandu valley
Farmers were well aware of the soil productivity status in their fields (Figure 3). For them, nutrient content in the soil as medium status has turned out to be less productive soil. Similarly, soil with high nutrient status as satisfactory and soil with very high nutrient status as productive soil. Chi-squared test for goodness of fit showed that the observed chi-squared value for two degrees of freedom and p-value of 0.002 was higher (i.e. 12.50) in comparison to the tabulated value (i.e. 12.43).

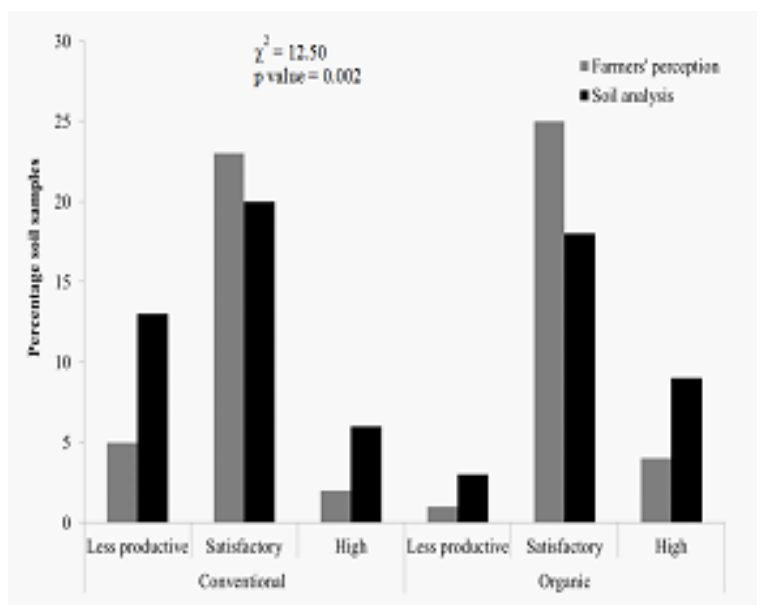

Fig. 3. Parity test on farmers' perception on soil productivity and soil analysis results (percentage of 30 soil samples each) in Kathmandu valley

As water is the critical factor for growing a crop, water availability was the main factor to select a piece of land for vegetable production. In addition to that, about $20 \%$ commercial farmers also made inquiry about soil fertility before choosing a field for vegetable production (Table 6).

Table 6. Reasons for choosing a particular piece of land for vegetable production among commercial organic and conventional farmers (percentage respondents out of 30 each) in Kathmandu valley

\begin{tabular}{l|l|l}
\hline Reason & $\begin{array}{l}\text { Organic farmers } \\
\text { (percentage) }\end{array}$ & $\begin{array}{l}\text { Consentional } \\
\text { farmers } \\
\text { (percentage) }\end{array}$ \\
\hline Water availability & 53.3 & 52.7 \\
Fertile land & 20.0 & 17.3 \\
\hline
\end{tabular}

From the Table 7, it was a general observation by organic farmers that organic farming gives higher yield in the year continuum. In contrast, about $25 \%$ 
conventional farmers observed requirement of higher amount of inputs to gain equal outputs as in the previous years.

Table 7. Trend of productivity as perceived by commercial organic and conventional farmers (percentage respondents out of 30 each) in Kathmandu valley

\begin{tabular}{l|l|l}
\hline Produc tivity status & $\begin{array}{l}\text { Organic } \\
\text { farmers } \\
\text { (percentage) }\end{array}$ & $\begin{array}{l}\text { Consentional } \\
\text { farmers } \\
\text { (percentage) }\end{array}$ \\
\hline $\begin{array}{l}\text { Need higher amount } \\
\text { of inputs than before }\end{array}$ & 10.0 & 26.7 \\
$\begin{array}{l}\text { Equal productivity } \\
\text { as before with equal } \\
\text { arnount of inputs }\end{array}$ & 33.3 & 30.0 \\
$\begin{array}{l}\text { Higher productivity } \\
\text { than before with } \\
\text { equal amount of } \\
\text { inputs }\end{array}$ & 56.7 & 43.3 \\
\hline
\end{tabular}

\section{Problems}

Conventional farmers were more concerned about soil fertility in comparison to the organic farmers (Figure 4). Nevertheless, soil fertility maintenance was not as serious problem as water management. More than $40 \%$ commercial vegetable growers were concerned for the water management.

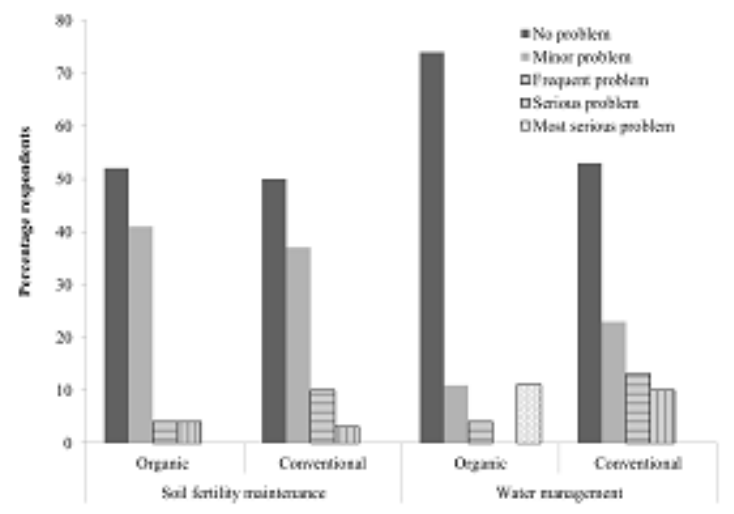

Fig.4. Relevance of soil fertility and water management problem in commercial organic and conventional farms (percentage respondents out of 30 each) in Kathmandu valley

\section{Advice}

About $50 \%$ of the respondents were asking for advice on soil fertility, fertiliser and irrigation management to the different advisory bodies (Fig. 5). Advice seeking habit was not different between organic and conventional vegetable farmers. Many commercial vegetable growing farmers were in contact with agricultural consultants (Figure 5).

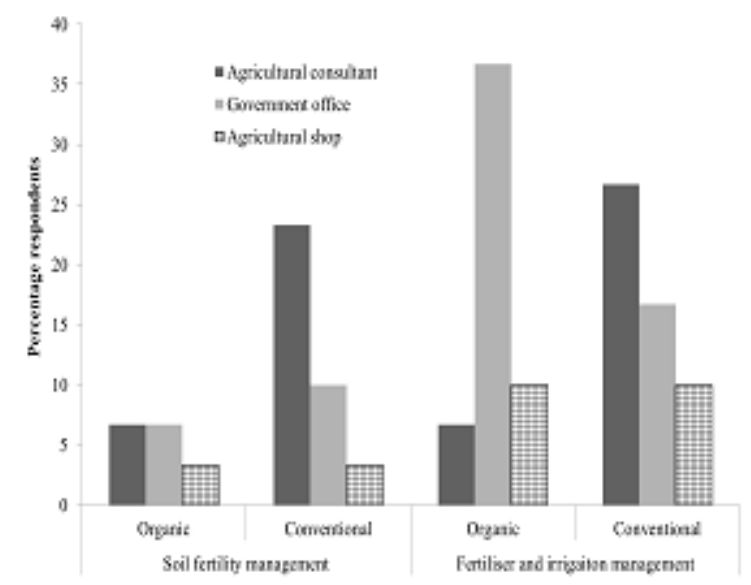

Fig.5. Resort for advice and information among commerical organic and conventional vegetable farmers (percentage respondents out of 30 each) in Kathmandu valley

\section{Crops}

Although, leguminous vegetable crops were cultivated by the commercial farmers, these crops did not find significant place in the commercial farms (Fig. 1). It was maybe due to either lack of knowledge (Shrestha et al. 2008) about contribution of legumes in soil nitrogen enrichment (Prasad \& Power 1997) or lack of organic consumers' demand for organic fresh leguminous vegetables.

Bastakoti (2011) used the modelling approach to calculate the possibility of supplying nitrogen and phosphorus through legume integration in the organic farm in the context of Chitwan district, Nepal. Calculations revealed with minimum $30 \%$ legume integration in the organic farm, nitrogen and phosphorus surplus can be decreased to minimum. Moreover, Badgley et al. (2007) revealed possibility of supplying all the required plant nitrogen from legumes.

\section{Soil properties}

On par with Schjønning et al. (2002) and Chirinda et al. (2010), we found non-significant difference in soil bulk density between organic and conventional farm 
(Table 3). Our results were in contrast with Liebig \& Doran (1999), it was maybe because they applied only chemical fertiliser in the conventional plots. In the current study, conventional farmers were also applying comparable amount of organic manure in the farm to those by organic farmers (Table 4). Schjønning et al. (2002) and Chirinda et al. (2010) applied only pig slurry in organic farm which did not contribute significant biomass in the soil to increase the bulk density.

In contrast to Zeiger \& Fohrer (2009), we found nonsignificant difference in the soil moisture content (Table 3). It was due to the rainy season during the soil sample collection period.

Organic vegetable farms had significantly higher bulk soil $\mathrm{pH}$ in comparison to conventional vegetable farms (Table 3). It was maybe due to no use of acidifying ammonium based nitrogen fertiliser in the organic farm (Table 4) (Brady \& Weil 2012). In addition, significantly higher amount of bone meal used by organic farmers in comparison to conventional vegetable growers also contributed to calcium in the soil.

Agreeing with Cardelli et al. (2004), soil organic matter content was significantly higher in amount in organic farm than in conventional farm (Table 3). Regular application of higher amount of organic manure in the organic fields than conventional fields (Table 4) increased soil organic matter content. In contrast to Shrestha (2013), who showed decreased organic manure application by the subsistence vegetable farmers, commercial farmers were applying recommended dose of organic manure in the vegetable farms.

Available soil nitrogen content in the conventional vegetable farms was almost double in comparison to the organic farms (Table 3). It was maybe due to application of ammonium based nitrogen fertiliser in the conventional farms (Table 4). Reconfirming Burger \& Jackson (2003), available form of nitrogen was maybe immobilised by more micro-organisms present in the organic farm than in the conventional farm. The cause for fewer micro-organisms in conventional farm was maybe application of toxic pesticides and chemical fertiliser (Elmholt \& Labouriau 2005).

Total soil nitrogen content was significantly higher in the conventional vegetable field in comparison to the organic field (Table 3). Significantly higher amount of chicken manure application in the conventional vegetable farms than in organic farms has contributed in this difference (Table 4). It was maybe because chicken manure contains relatively higher percentage of nitrogen than other manures (Shrestha 2014). Our results reconciled Clark et al. (1998) and Liebig \& Doran (1999) in which they revealed significantly higher total soil nitrogen content in organic farm than in conventional farm. In this study, it was maybe the duration of the farming which was on an average five and three year only in the organic and conventional farming respectively (Table 1).

On par with Clark et al. (1998), available soil potassium content was significantly higher in amount in the organically managed field than in conventionally managed field (Table 3). In this study, it was maybe due to the application of higher amount of urban compost containing higher amount of potassium (Karki 2003) in the organic farm (Table 4).

\section{Fertiliser use}

Commercial conventional vegetable farmers in Kathmandu valley were applying standard recommended dose of chemical fertiliser (Table 4) for vegetable production (ABPSD 2012). The amount of chemical fertiliser added was not as high as is in practice in the other countries like China. Chen et al. (2004) disclosed very high amount of macro-nutrients i.e. $800 \mathrm{~kg}$ nitrogen, $200 \mathrm{~kg}$ phosphorus and $200 \mathrm{~kg}$ potassium per hectare being applied for a vegetable crop mainly in the form of chemical fertiliser in Beijing region. Excessive application of chemical fertiliser creates a risk of soil degradation and causes environmental pollution (Tilman et al. 2002) which seems to be far less in commercial conventional vegetable farms in Nepal.

\section{Farmers' knowledge}

In general, farmers used only three types of soil texture i.e. coarse, medium and fine textural class (Table 1, Figure 2). Coarse textured soil included sandy loam; medium textured soil included loam, silt and silt loam and fine textured soil included clay, sandy clay loam, silt clay loam and clay in this study. Other soil textural classes were not determined during textural analysis.

Confirming Desbiez et al. (2004), though soil fertility status was medium in condition, farmers categorised 
those soil as less productive soil (Figure 3). It was maybe because for farmers, crop yield was the main yardstick to categorise soil productivity (Lima et al. 2011).

Reformulating Matthews \& Pilbeam (2005), our results revealed that farmers were able to perceive the changes in the soil productivity. Confirming Lotter (2003) who showed increasing crop productivity in long term, in this study organic farmers perceived increasing trend of soil productivity (Table 7). Conventional farmers complained about requirement of higher amount of inputs than in the past years to get the same level of production from the field (Table 7). It was maybe due to destruction of the soil structure, loss of soil biota, and accumulation of toxic compounds in the soil in the conventional farm soil (Eyhorn et al. 2002, Hall \& Moffitt 2002, MoAC 2008).

Organic farming is a good option for sustainable soil management. Conventional farmers in Nepal were applying very small doses of chemical fertilisers in comparison to those in the countries like China. Moreover, application of comparable amount of organic manure in the conventional farm as in the organic farm has maintained soil fertility. For maintaining soil nitrogen, growing of leguminous crops can be a sustainable option.

\section{Acknowledgements}

The author is indebted to all the respondent farmers for giving their precious time and invaluable information. The author is grateful to the University Grants Commission (UGC), Nepal for providing faculty research grant to conduct this research. Acknowledgement is also due to Prof. Dr. Tej Bahadur K.C. for his suggestions during manuscript preparation.

\section{References}

ABPSD. 2012. Vegetable farming technology (in Nepali). AgriBusiness Promotion and Statistics Division (ABPSD), Ministry of Agriculture and Cooperatives, Government of Nepal, Singha Durbar, Kathmandu.

ADB 7762-NEP. 2013. Preparation of the agricultural development strategy $(A D S)$ : Final report. Asian Development Bank (ADB), Kathmandu.

Andrist-Rangel, Y., A. Edwards, S. Hillier and I. Öborn. 2007. Long-term $\mathrm{K}$ dynamics in organic and conventional mixed cropping systems as related to management and soil properties. Agriculture, Ecosystems and Environment 122: 413-426.

Badgley, C., J. Moghtader, E. Quintero, E. Zakem, M.J. Chappell, K. Aviles-Vazquez, A. Samulon and I. Perfecto. 2007. Organic agriculture and the global food supply. Renewable agriculture and food systems 22 : 86-108.

Bastakoti, N. 2011. Comparison of conventional and organic farming systems in Chitwan: Empirical and bioeconomic modeling apporach. Master thesis, Wageningen University and Research Centre, Wageningen, The Netherlands.

Bhandari, D.R. 2006. Community level organic vegetable production program: an experience of Kathmandu district. In: Proceedings of a first national workshop on organic farming, 12 - 14 June 2006 (Baisakh 28 30, 2063 B.S.). Directorate of Agriculture Extension, Kirtipur, Kathmandu.

Birkhofer, K., T.M. Bezemer, J. Bloem, M. Bonkowski, S. Christensen, D. Dubois, F. Ekelund, A. Fließbach, L. Gunst, K. Hedlund, P. Ma“der, J. Mikola, C. Robin, H. Seta" la“, F. Tatin-Froux, W.H. Van der Putten and S. Scheu. 2008. Long-term organic farming fosters below and aboveground biota: Implications for soil quality, biological control and productivity. Soil Biology and Biochemistry 40: 2297-2308.

Brady, N.C. and R.C. Weil. 2012. The nature and properties of soils. $14^{\text {th }}$ ed. Dorling Kindersley India Pvt. Ltd., India.

Burger, M. and L.E. Jackson. 2003. Microbial immobilization of ammonium and nitrate in relation to ammonification and nitrification rates in organic and conventional cropping systems. Soil Biology and Biochemistry 35: 29-36.

Cardelli, R., R. Levi-Minzi, A. Saviozzi and R. Riffaldi. 2004. Organically and conventionally managed soils: biochemical characteristics. Journal of Sustainable Agriculture 25: 63-74.

Chen, Q., X. Zhang, H. Zhang, P. Christie, X. Li, D. Horlacher and H.P. Liebig. 2004. Evaluation of current fertilizer practice and soil fertility in vegetable production in the Beijing region. Nutrient Cycling in Agroecosystems 69: 51-58.

Chirinda, N., J.E. Olesen, J.R. Porter and P. Schjonning. 2010. Soil properties, crop production and greenhouse gas emissions from organic and inorganic fertilizerbased arable cropping systems. Agriculture, Ecosystems and Environment 139: 584-594.

Clark, M.S., W.R. Horwath, C. Shennan and K.M. Scow. 1998. Changes in soil chemical properties resulting from organic and low-input farming practices. Agronomy Journal 90: 662-671.

Clark, M.S., W.R. Horwath, C. Shennan, K.M. Scow, W.T. Lantni and H. Ferris. 1999. Nitrogen, weeds and water as yield-limiting factors in conventional, low-input, 
Gautam Shrestha/Soil properties and soil management.......

and organic tomato systems. Agriculture, Ecosystems and Environment 73: 257-270.

Deria, A.M., R.W. Bell and G.W. O'Hara. 2003. Organic wheat production and soil nutrient status in a mediterranean climatic zone. Journal of Sustainable Agriculture 21: 21-47.

Desbiez, A., R. Matthews, B. Tripathi and J. Ellis-Jones. 2004. Perceptions and assessment of soil fertility by farmers in the mid-hills of Nepal. Agriculture, Ecosystems and Environment 103: 191-206.

Elmholt, S. and R. Labouriau. 2005. Fungi in Danish soils under organic and conventional farming. Agriculture, Ecosystems and Environment 107: 65-73.

Eyhorn, F., M. Heeb and G. Wieidmann. 2002. IFOAM Training manual for organic agriculture in the Tropics: Theory, transparencies, didactic apporach. International Federation of Organic Agriculture Movements (IFOAM), Research institute of organic agriculture (FiBL), CABI Bioscience, Agrecol Afique (Senegal), Agrecol Andes (Bolivia) and INOCERT (India).

FRSRD. 1980. Standard methods of analysis for soil, plant tissue, water and fertilizer. Philippine Council for Agriculture and Resources Research (FRSRD), Los Banos, Laguna.

Hall, D. and L. Moffitt. 2002. Adoption and diffusion of sustainable food technology and policy. In: Economics of pesticides, sustainable food production and organic food markets (Eds. D. Hall and L. Moffitt) . Elsevier Science Ltd. Pp. 3-18.

Karki, K.B. 2003. Status of potassium in intensively cultivated soils of Kathmandu valley. Nepal Journal of Science and Technology 5: 83 - 90.

Liebig, M.A. and J.W. Doran. 1999. Impact of organic production practices on soil quality indicators. Journal of Environmental Quality 28: 1601-1609.

Lima, A.C.R., W.B. Hoogmoed, L. Brussaard and F. Sacco dos Anjos. 2011. Farmers' assessment of soil quality in rice production systems. NJAS - Wageningen Journal of Life Sciences 58: 31-38.

Lotter, D.W. 2003. Organic agriculture. Journal of Sustainable Agriculture 21: 59-128.

Mader, P., A. Flieâbach, D. Vubois, L. Gunst, P. Fried and U. Niggli. 2002. Soil fertility and biodiversity in organic farming. Science 296: 1694-1697.

Matthews, R.B. and C. Pilbeam. 2005. Modelling the longterm productivity and soil fertility of maize/millet cropping systems in the mid-hills of Nepal.
Agriculture, Ecosystems and Environment 111: 119139.

MoAC. 2008. Nepalese standards of organic agriculture. Ministry of Agriculture and Cooperative (MoAC), Government of Nepal, Kathmandu, Nepal.

Monokrousos, N., E.M. Papatheodorou, J.D. Diamantopoulos and G.P. Stamou. 2006. Soil quality variables in organically and conventionally cultivated field sites. Soil Biology and Biochemistry 38: 12821289.

Offermann, F. and H. Nieberg. 2000. Economic performance of organic farms in Europe. Universität Hohenheim, Institut für Landwirtschaftliche Betriebslehre.

Prasad, R. and J.F. Power. 1997. Soil fertility management for sustainable agriculture. CRC Press Inc.

Romanyà, J. and P. Rovira. 2009. Organic and inorganic P reserves in rain-fed and irrigated calcareous soils under long-term organic and conventional agriculture. Geoderma 151: 378-386.

Schjønning, P., S. Elmholt, L.J. Munkholm and K. Debosz. 2002. Soil quality aspects of humid sandy loams as influenced by organic and conventional long-term management. Agriculture, Ecosystems and Environment 88: 195-214.

Shrestha, G. 2012. A practical manual on introductory soil science. HICAST, Kathmandu.

Shrestha, G. 2013. Decreased organic manure application in Kathmandu valley vegetable fields threatens the soil productivity. Nepalese Journal of Agricultural Sciences 11: 62-70.

Shrestha, G. 2014. A practical manual on fertilisers, manure and sustainable soil management. HICAST, Kathmandu.

Shrestha, G., K.B. Karki and G.D. Bhatta. 2008. Role of legume intercropping in sustainable farming in midhills of Nepal. In: Third proceedings of Society of Agricultural Scientists (SAS) : Agricultural research for poverty alleviation and livelihood enhancement. 27-29 August. Kathmandu, Nepal. p. 58-64.

Tilman, D., K.G. Cassman, P.A. Matson, R. Naylor and S. Polasky. 2002. Agricultural sustainability and intensive production practices. Nature 418: 671-677.

Zeiger, M. and N. Fohrer. 2009. Impact of organic farming systems on runoff formation processes - A long-term sequential rainfall experiment. Soil and Tillage Research 102: $45-54$.

Zurick, D. and A. Rose. 2009. Landscape change in Kathmandu valley, Nepal. Focus on Geography 51: 7-16. 
Nepal Journal of Science and Technology Vol. 15, No.1 (2014) 13-22 